\title{
Development of a TiNbTaMoZr-Based High Entropy Alloy with Low Young's Modulus by Mechanical Alloying Route
}

\author{
Juliette Normand $^{1}$, Rocío Moriche ${ }^{2} \mathbb{D}$, Cristina García-Garrido ${ }^{3}$, \\ Ranier Enrique Sepúlveda Ferrer ${ }^{4}\left(\right.$ i) and Ernesto Chicardi ${ }^{4, *}$ (D) \\ 1 SIGMA Clermont, 63178 Aubière, France; juliette.normand@sigma-clermont.fr \\ 2 Departamento de Física de la Materia Condensada, Universidad de Sevilla, 41080 Sevilla, Spain; \\ rmoriche@us.es \\ 3 Instituto Andaluz del Patrimonio Histórico (IAPH), 41092 Sevilla, Spain; \\ cristina.g.garrido@juntadeandalucia.es \\ 4 Departamento de Ingeniería y Ciencia de los Materiales y del Transporte, Universidad de Sevilla, \\ 41092 Sevilla, Spain; rsepulveda@us.es \\ * Correspondence: echicardi@us.es; Tel.: +34-954-482-279
}

Received: 14 October 2020; Accepted: 29 October 2020; Published: 1 November 2020

check for updates

\begin{abstract}
In this work, an equiatomic TiNbTaMoZr-based high-entropy alloy (HEA) has been developed by a powder metallurgy route, which consists of a process of combined one-step low-temperature mechanical milling starting from the transition metals as raw materials and a subsequent pressureless sintering. In this way, the optimized synthesized specimen, after $10 \mathrm{~h}$ of milling time, showed two different body-centered cubic (bcc) TiNbTaMoZr alloys, which, after sintering at $1450{ }^{\circ} \mathrm{C}, 1 \mathrm{~h}$ of dwell time and a heating and cooling rate of $5{ }^{\circ} \mathrm{C} \mathrm{min}-1$, it remained formed as two bcc TiNbTaMoZr-based HEAs. This material, with micrometric and equiaxed particles, and with homogeneously distributed phases, presented a Young's modulus that was significantly higher $(5.8 \mathrm{GPa})$ and lower $(62.1 \mathrm{GPa})$ than that of the usual commercially pure (cp) Ti and Ti6Al4V alloy used for bone-replacement implants. It also presented similar values to those of the HEAs developed for the same purpose. These interesting properties would enable this TiNbTaMoZr-based HEA to be used as a potential biomaterial for bulk or porous bone implants with high hardness and low Young's modulus, thereby preventing the appearance of stress-shielding phenomena.
\end{abstract}

Keywords: high-entropy alloys; titanium; biomaterials; bone tissue engineering; mechanical alloying; Young's modulus

\section{Introduction}

High-entropy alloys (HEAs) form a new group of metallic materials that has been under investigation over the past few decades. Unlike conventional alloys based on a single main element, HEAs are composed of at least five elements in near-equiatomic proportions [1]. In 2013, Yeh [2] proposed HEAs as those alloys with a configurational entropy of mixing $\left(\Delta S_{\text {mix }}\right)$ above $1.5 R$. For an equiatomic alloy, $\Delta S_{\text {mix }}$ is defined as:

$$
\Delta S_{\text {mix }}=R \ln (n)
$$

with $n$ as the number of elements and $R$ the gas constant. Therefore, in order to obtain a $\Delta S_{\text {mix }}$ above $1.5 \mathrm{R}$, an HEA would have to contain at least five elements. 
The success of these new alloys is mainly based on their high stability, provided by the high mixing entropies $\left(\Delta S_{\text {mix }}\right)$ for solid solutions, which compensate for the positive enthalpy of mixing $\left(\Delta \mathrm{H}_{\text {mix }}\right)$ to obtain a negative Gibbs free energy of mixing $\left(\Delta \mathrm{G}_{\text {mix }}\right)$ [2].

$$
\Delta G_{m i x}=\Delta H_{m i x}-T \Delta S_{m i x}
$$

To promote the formation of HEAs, Zhang et al. in 2008 [3] and Guo et al. in 2013 [4] also point out the importance of the atomic size difference $(\delta)$, according to Equation (3).

$$
\delta=100 \sqrt{\sum_{i}^{n} x_{i}\left(1-\frac{r_{i}}{\bar{r}}\right)^{2}}
$$

where $x_{i}$ and $r_{i}$ are the atomic fraction and radius of the $\mathrm{i}^{\text {th }}$ element and $\bar{r}$ is the average atomic radius. The solid solution was predicted to occur for approximately $\delta<6.4 \%$ associated with the enthalpy and entropy of mixing of $-20 \mathrm{~kJ} \cdot \mathrm{mol}^{-1} \leq \Delta \mathrm{H}_{\text {mix }} \leq 5 \mathrm{~kJ} \cdot \mathrm{mol}^{-1}$ and $12 \mathrm{~J} \cdot \mathrm{mol}^{-1} \cdot \mathrm{K}^{-1} \leq \Delta \mathrm{S}_{\text {mix }} \leq 17.5 \mathrm{~J} \cdot \mathrm{mol}^{-1} \cdot \mathrm{K}^{-1}$ respectively [3]. All these parameters have also been corroborated more recently by Ye et al. [5].

Therefore, as a consequence of the expected stabilization of the solid solution and microstructure, a variety of other unique properties arise from their multi-atom compositions [6,7]. For example, the complex and random distribution of atoms generates distortion and stress in the lattice, which lead to an increase of toughness, strength and wear resistance of the material [2,8]. Their superior mechanical properties compared to conventional alloys have attracted various engineering fields, such as the transportation and energy industries, for their use in structural or refractory applications. Certain literature is devoted to the study of HEAs as potential materials for these industries [8-10].

Regarding the biomedical field, these innovative HEAs could provide a good choice of material since they comply with the strict criteria for orthopaedic applications. Bone replacements must be biocompatible and must show no cytotoxicity and offer good resistance to corrosion within the body environment [11]. They should also exhibit a low Young's modulus, which is associated with great strength, high elasticity and high wear resistance to mimic bone properties and prevent the stress-shielding effect that causes bone resorption and the loosening of implants [12-14]. The currently used Ti-based alloys, mainly Ti6Al4V, satisfy most of these criteria but exhibit an excessively high Young's modulus $(\mathrm{E}=112 \mathrm{GPa})$ compared to human bones $(\mathrm{E}=3-40 \mathrm{GPa})$ [14]. Moreover, $\mathrm{Al}$ and $\mathrm{V}$ have proven to be toxic to the body [15]. Therefore, the biocompatible elements such as $\mathrm{Ta}, \mathrm{Nb}, \mathrm{Mo}, \mathrm{Zr}$, $\mathrm{Mg}$ and $\mathrm{Sn}$ are studied herein as Ti alloying elements for orthopaedic uses $[15,16]$.

Furthermore, to reduce the value of Young's modulus, one of the strategies is to develop $\beta$-Ti based alloys (body-centered cubic phase), which possess greater strength and a lower Young's modulus than the $\alpha$ (hexagonal closed-packed structure) Ti-based alloys [17-19]. The allotropic transformation from $\alpha$ to $\beta$ phases takes place at $882.3{ }^{\circ} \mathrm{C}$ although the addition of alloying elements, known as $\beta$-stabilizers, such as $\mathrm{Nb}$ and $\mathrm{Ta}$, can lower this temperature [11,19]. Since it is known that $\mathrm{Ti}, \mathrm{Nb}$ and Ta possess complete mutual solubility and perfect biocompatibility, the association of these three elements has attracted interest as a basis for the development of alloys [20-22]. The formation of a HEA by combining this basis with two or more biocompatible metals would lead to a material with an even higher yield strength and lower Young's modulus, thereby providing a material that satisfies the orthopaedic criteria in terms of mechanical properties, non-toxicity and corrosion resistance.

The synthesis of the HEAs is essentially obtained by the arc-melting process, which can achieve sufficiently high temperatures to melt most of the metals used. This method usually leads to a heterogeneous microstructure with a major segregation of the atoms [23]. A less common processing route to synthesis the HEAs is the mechanical alloying (MA). The MA route is a solid-state high-energy ball milling process, which is a simple, reproducible, scalable and inexpensive synthesis route that would enable the HEA to be obtained in a powder form in contrast with the arc-melting process. The particles are plastically deformed, fractured and welded at high speed, which allows diffusion 
of the different elements into the particles and promotes nanocrystallization. Better control of the structure and constitution of homogeneous materials can therefore be achieved [24].

The formation of a nominal equiatomic HEA composed of the biocompatible $\mathrm{Ti}, \mathrm{Nb}, \mathrm{Ta}, \mathrm{Mo}$ and $\mathrm{Zr}$ metals has previously been completed using the arc-melting process by Wang and $\mathrm{Xu}$ [25], Todai et al. [26], and Nagase et al. [27]. They obtained a structure formed of two bcc alloys, with dendritic morphology and heterogeneous composition, due to the segregations of metals atoms during solidification; however, a noticeably high Young's modulus of 133 GPa was also reported [25].

For a hypothetical equiatomic HEA composed of the five elements employed, that is, $\mathrm{Ti}, \mathrm{Nb}, \mathrm{Ta}, \mathrm{Mo}$ and $\mathrm{Zr}$, at $25^{\circ} \mathrm{C}$, the $\Delta \mathrm{S}_{\text {mix }}$ and $\Delta \mathrm{H}_{\text {mix }}$ were calculated as $13.4 \mathrm{~J} \cdot \mathrm{mol}^{-1} \cdot \mathrm{K}^{-1}$ and $-1.6 \mathrm{~kJ} \cdot \mathrm{mol}^{-1}$ respectively, thereby giving a $\Delta \mathrm{G}_{\text {mix }}$ of $-5.6 \mathrm{~kJ} / \mathrm{mol}$ following Equations (1)-(3). This negative result predicts an elevated stability for the alloy with a calculated atomic size difference $\delta$ equal to $4.9 \%$. These values are in good agreement with the ranges determined by Zhang, et al. [3] $\left(12 \leq \Delta \mathrm{S}_{\text {mix }} \leq 17.5 \mathrm{~J} \cdot \mathrm{mol}^{-1} \cdot \mathrm{K}^{-1}\right.$; $-20 \leq \Delta \mathrm{H}_{\text {mix }} \leq 5 \mathrm{~kJ} / \mathrm{mol}$ and $\left.\delta<6.4 \%\right)$. This analysis suggests the possible formation of the expected TiNbTaMoZr HEA by MA, from a thermodynamic perspective.

Therefore, the aim of this work is to study the synthesis, characterize the final microstructure and determined the mechanical properties of the TiNbTaMoZr based HEA by using the alternative mechanical alloying route, in order to ascertain the suitability of this material for its use as biomaterial for bulk of porousorthopedic bone implant developed by additive manufacturing techniques [28].

\section{Experimental Procedure}

\subsection{Development of the TiNbTaMoZr-Based HEA.}

Equiatomic powder mixtures of titanium ( $99 \%$ purity, $<325$ mesh, Strem chemicals, Newburyport, MA, USA), tantalum ( $99.6 \%$ purity, $<325$ mesh, Strem chemicals, Newburyport, MA, USA), niobium (99.8\% purity, <325 mesh, Strem chemicals, Newburyport, MA, USA), molybdenum (99\% purity, $<325$ mesh, Strem chemicals, Newburyport, MA, USA) and zirconium (99.5\% purity, 50 mesh, Strem chemicals, Newburyport, MA, USA) were used as the raw materials to synthesize the TiNbTaMoZr-based HEA.

The TiNbTaMoZr powder mixtures were milled at various milling times between 1 and $20 \mathrm{~h}$, with a spinning rate of $600 \mathrm{rpm}$ in a planetary ball mill (P7, Fritsch), by cycles of $15 \mathrm{~min}$ ON and $15 \mathrm{~min}$ OFF to prevent an excessive increase in temperature and also to prevent the welding of powders, under an inert argon gas atmosphere at $4 \mathrm{~atm}$. (Argon, Linde Group Spain, Valencia, Spain). A $45 \mathrm{~mL}$ steel jar and 7 steel balls $(\varnothing=15 \mathrm{~mm}$ and $\mathrm{m}=13.5 \mathrm{~g}$ ) were used with a ball-to-powder ratio (BPR) equal to 10 . The as-milled powders were labeled as $p T N T M Z x h$, where $p$ and $x$ correspond to powders and the hours of milling time respectively.

The pTNTMZ powders selected were compacted using a uniaxial press ( 2 tons) and, subsequently, a cold isostatic press $(200 \mathrm{MPa})$. The green bodies were sintered in a horizontal tubular furnace (IGM1360 model No. RTH-180-50-1H, AGNI, Aechen, Germany) under an Argon flow $\left(\mathrm{H}_{2} \mathrm{O} 68 \mathrm{ppm}\right.$ and $\mathrm{O}_{2} 62 \mathrm{ppm}$, Linde Group Spain, Valencia, Spain) at $1450{ }^{\circ} \mathrm{C}$ and $1550{ }^{\circ} \mathrm{C}$ for $1 \mathrm{~h}$ to study the microstructure evolution and the possible transformation of the phases. The heating and cooling rates used were $5{ }^{\circ} \mathrm{C} \cdot \mathrm{min}^{-1}$. The final cylindrical specimens of $20 \mathrm{~mm}$ in diameter and $5 \mathrm{~mm}$ in height were obtained. These sintered specimens were labeled as sTNTMZ_y ${ }^{\circ} \mathrm{C}$, where $s$ and $y$ correspond to sintered and sintering temperature respectively.

\subsection{Microstructural Characterization of the TiNbTaMoZr-Based HEA.}

X-ray diffraction (XRD) patterns of the as-synthesized pTNTMZxh powders and the as-sintered sTNTMZ_y ${ }^{\circ} \mathrm{C}$ specimens were recorded using a PANalytical $X^{\prime}$ Pert Pro instrument (Malvern Panalytical Ltd, Malvern, UK) equipped with a Bragg-Brentano $\theta / \theta$ geometry, a $\mathrm{Cu} \mathrm{K} \alpha$ radiation source $(45 \mathrm{kV}$, $40 \mathrm{~mA}$ ), a secondary $\mathrm{K} \beta$ filter and an $X^{\prime}$ Celerator detector. The XRD patterns were obtained by scanning between 20 and $120^{\circ}$ of the 2theta degree with $0.03^{\circ}$ steps and a counting time of $800 \mathrm{~s} \cdot \mathrm{step}^{-1}$. 
The free-access Crystallography Open Database (COD) was employed to elucidate the phases developed with the corresponding structures and space-group symmetries (SGSs). A lanthanum hexaboride, LaB6 (Standard Reference Material 660b, NIST) pattern was used to calibrate the positions of the diffraction lines.

Scanning electron microscopy (SEM) images in secondary electron mode were obtained using a Hitachi S-4800 (Hitachinaka, Japan) field at a voltage of $5 \mathrm{kV}$ on the specimens. The $\mathrm{Ti}, \mathrm{Nb}, \mathrm{Ta}$, $\mathrm{Mo}, \mathrm{Zr}$ and $\mathrm{Fe}$ (coming from the milling media) contents were measured by energy-dispersive $\mathrm{X}$-ray spectrometry (EDS) point analysis using a detector coupled with SEM at a voltage of $20 \mathrm{kV}$. All SEM-EDS maps were collected under a voltage of $30 \mathrm{kV}$.

High-resolution transmission electron microscopy (HRTEM) images were obtained by using an FEI Talos ${ }^{\text {TMF}}$ 200S scanning/transmission electron microscope (Hillsboro, OR, USA) at a voltage of $200 \mathrm{kV}$ (point resolution $=0.25 \mathrm{~nm}$ ). The micrograph analysis, lattice spacing, fast Fourier transform (FFT) and phase interpretation were performed with the Gatan Digital micrograph software (Gatan Inc., Pleasanton, CA, USA). The as-milled $p T N T M Z$ powder sample was dispersed in ethanol and droplets of the suspension were deposited onto a PELCOßCopper grid with pure carbon film.

\subsection{Micromechanical Behavior of the TiNbTaMoZr-Based HEA.}

The micromechanical behavior of the sintered TiNbTaMoZr-based HEA was analyzed by instrumented microindentation tests. Static micromechanical tests were performed in a MTR3/50-50/NI Microtest durometer machine (Microtest, Madrid, Spain) using a Vickers indenter. The maximum load was $1 \mathrm{~N}$ with a load rate of $0.5 \mathrm{~N} / \mathrm{min}$ and a dwell time of $5 \mathrm{~s}$.

The microhardness and Young's modulus were calculated from the resulting loading-unloading curves following the method published by Oliver and Pharr [29]. The microhardness (H) of the HEA was calculated from the maximum load $\left(P_{\max }\right)$ and the contact area $(A)$, calculated from the depth of contact between the indenter and the sample surface $\left(h_{c}\right)$, in accordance with Equation (4):

$$
H=\frac{P_{\max }}{A}
$$

The effective elastic modulus $\left(E_{e f f}\right)$ was calculated by the slope of the unloading P-h curve $(S)$ and a correction factor dependent on the indenter $(\beta)$, using the Equation (5):

$$
E_{e f f}=\frac{S}{\beta \frac{2}{\sqrt{\pi}} \sqrt{A}}
$$

Finally, the elastic modulus $(E)$ was calculated from $E_{\text {eff }}$ while taking into account the contribution of the elastic modulus $\left(E_{i}\right)$ and Poisson's ratio of the indenter $\left(v_{i}\right)$ following Equation (6):

$$
E=\frac{\left(1-v^{2}\right)}{\frac{1}{E_{e f f}}-\frac{\left(1-v_{i}^{2}\right)}{E_{i}}}
$$

\section{Results and Discussion}

\subsection{Synthesis and Characterization of the TiNbTaMoZr-Based HEA.}

The X-ray diffraction (XRD) patterns obtained for the different as-synthesized pTNTMZ specimens, milled for between 1 and $20 \mathrm{~h}$, are shown in Figure $1 \mathrm{a}$. It should be noted that pTNTMZ2h, pTNTMZ3h, pTNTMZ5h and pTNTMZ6h have been excluded from the figure for the purpose of simplification and due to no substantial difference being found. Thus, for PTNTMZ1h, three phases could be indexed, that is, a hexagonal close-packed (hcp) structure, with P63/mmc SGS, corresponding to the elemental Zr (COD no. 9008523) and two body-centered cubic (bcc) structures with Im3m SGS. Both bcc structures can be assigned to elemental $\mathrm{Nb}$ or Ta for the first bcc, and to elemental Mo for the second bcc. Initially, 
$\mathrm{Nb}$ and Ta could rapidly form a solid solution since they have the same crystal structure (COD no. 1539041 and 1541266 respectively), a similar lattice parameter, and equivalent covalent radii, while Mo (COD no. 9008543) have a distinguished lattice parameter. Regarding the magnification of the XRD patterns around the (110) peak of the $\mathrm{Nb}$, Ta and Mo in pTNTMZ1h (Figure 1b), a displacement to a lower 2theta degree can be observed, which suggests that both bcc phases are modifying their compositions, attributable to an evolution from elemental $\mathrm{Nb}$, Ta and Mo to two bcc- 1 and bcc- 2 alloys (dotted lines in Figure 1b). Taking into account the total absence of any peaks corresponding to the elemental Ti (P63/mmc SGS, COD no. 9008517) in the pTNTMZ1h XRD pattern, a plausible explanation to the formation of both bcc-1 and bcc-2 alloys is the incorporation of Ti atoms (with the smaller covalent radii) to both bcc structures due to the high Ti solubility in the $\mathrm{Nb}$ and $\mathrm{Ta}$ bcc structure, and to the Ti partial solubility in Mo, according to the corresponding binary phase diagrams [30].

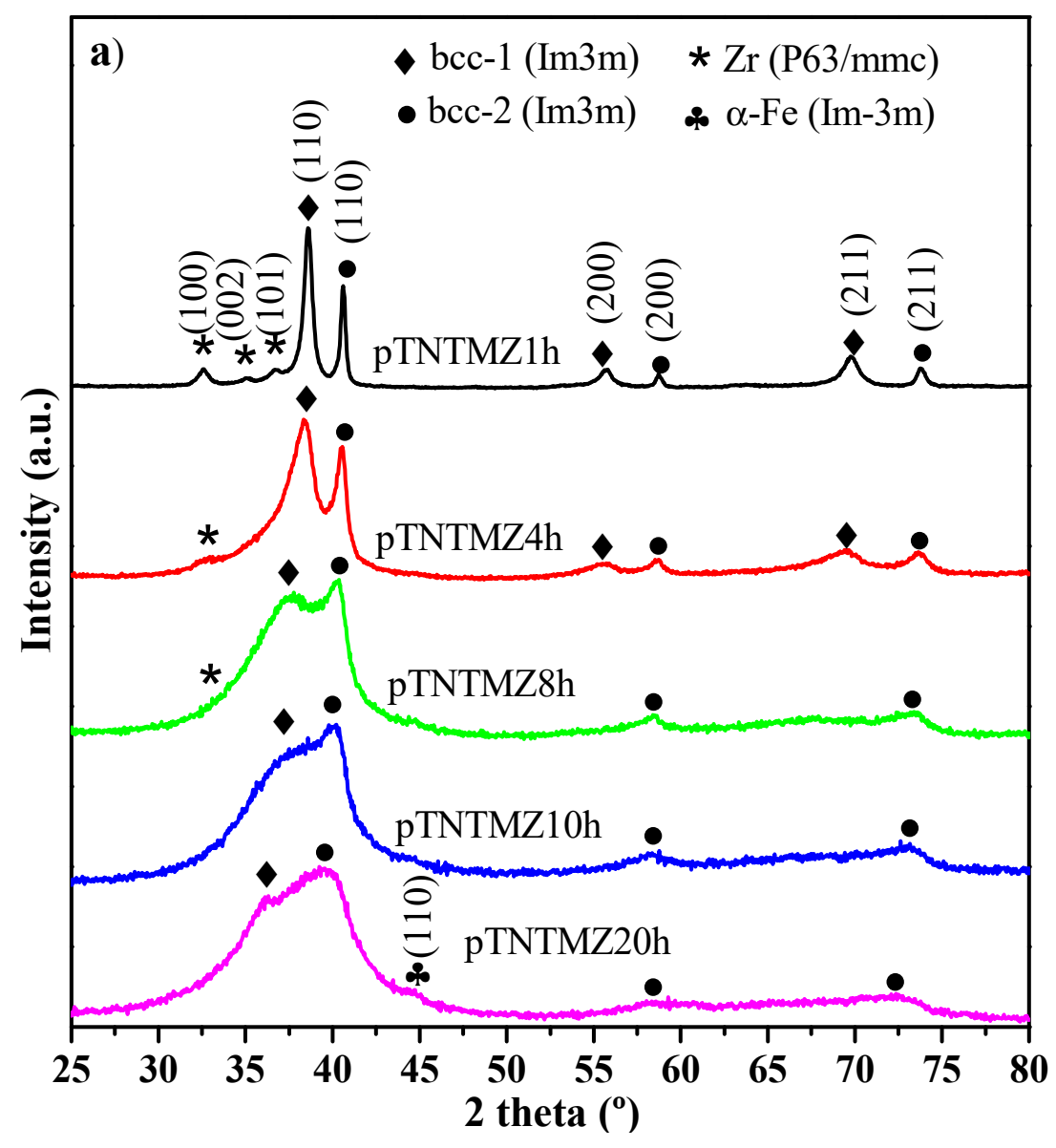

Figure 1. Cont. 

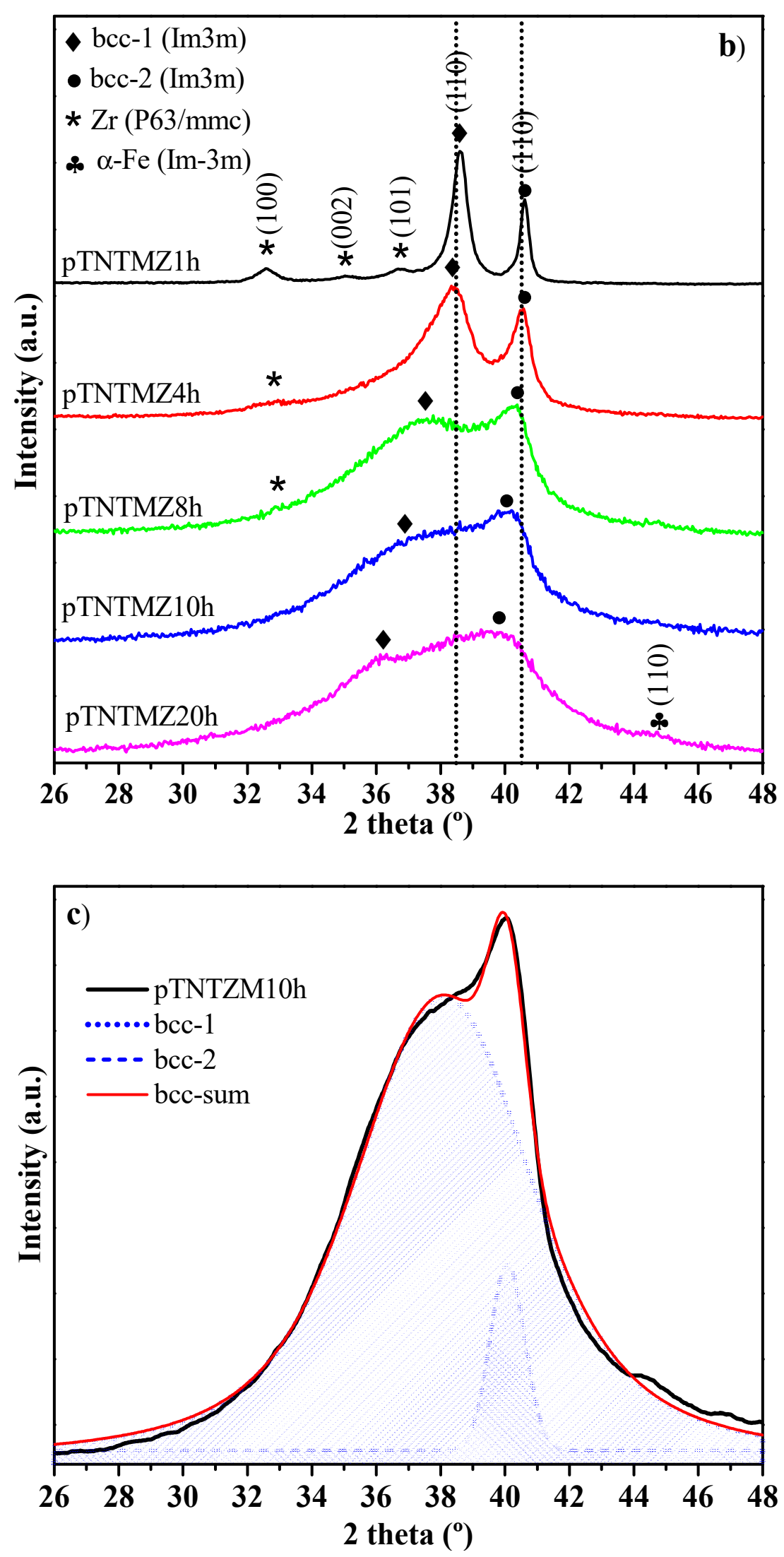

Figure 1. (a) XRD patterns showing the pTNTMZ specimens milled between 1 and $20 \mathrm{~h}$. (b) Magnification of all XRD patterns and (c) fitting for the pTNTMZ10h in the $26-48^{\circ} 2 \theta$ range and around the (110) crystallographic planes for the both two bcc- 1 and bcc- 2 alloys. The corresponding crystallographic planes for each phase are marked between brackets. Dotted lines are used to highlight the shift in the XRD peaks. 
When the milling time was increased, from 2 to $10 \mathrm{~h}$, the intensity of Zr peaks gradually diminished and the corresponding peaks for the two bcc-1 and bcc-2 alloys underwent a shift to a lower 2theta degree. After $10 \mathrm{~h}$ of milling time, no $\mathrm{Zr}$ peaks were detected, as can be observed in Figure $1 \mathrm{~b}$. These inspections suggests that, during milling, $\mathrm{Zr}$ atoms (with the higher covalent radii) seemed to be constantly incorporated into the bcc matrices, and the two bcc alloys were completely formed after $10 \mathrm{~h}$. Figure 1c shows the deconvolved XRD signal of the pTNTMZ10h pattern around the (110) bcc peaks, where the two bcc- 1 and bcc- 2 alloys were visible.

At $20 \mathrm{~h}$ of milling time, the bcc- 1 and bcc-2 alloys continued to shift slightly to a lower 2theta degree, suggesting a short-length redistribution of elements. However, at this longest milling time, the presence of Fe (coming from the stainless-steel milling media) was detected (bcc structure, Im3m SGS, COD no. 9008536). This presence is an undesirable aspect of the expected TiNbTaMoZr HEA as a potential biomaterial for a permanent bone-replacement implant. Iron is a biodegradable element [31-33], whose significant incorporation into the alloy might reduce mechanical performance due to the possible formation of porosity. This aspect constitutes a technological limitation that makes it unsuitable to apply longer milling times.

Therefore, regarding the complete formation in two bcc- 1 and bcc- 2 alloys and the absence of the undesirable Fe, the pTNTMZ10h pattern was selected as the optimal synthesized specimen for its later consolidation. No oxidized metallic phases were indexed, which initially suggests that the mechanical alloying process was correctly carried out in the absence of oxygen.

Subsequently, lattice parameters were calculated from the (110) major peaks of both bcc-1 and bcc-2 alloys. Their evolution throughout their milling time is shown in Figure 2. It can be confirmed how the lattice parameters increase as the alloying of the different elements progresses to the bcc structures. At $10 \mathrm{~h}$ of milling time, for pTNTMZ10h, chosen as the optimized as-synthesized specimen, the lattice parameters were calculated as $0.343 \mathrm{~nm}$ for the bcc- 1 alloy and $0.319 \mathrm{~nm}$ for the bcc- 2 alloy. Thus, the theoretical value, $0.335 \mathrm{~nm}$, determined by the mixing law and by the different references in the COD of the bcc elemental transition metals (Ti (high-temperature allotrope, COD no. 9008554), $\mathrm{a}=3.3065 \AA$; Nb (COD no. 1539041), $\mathrm{a}=3.3063 \AA$; Ta (COD no. 1541266), $\mathrm{a}=3.3026 \AA$; Mo (COD no. 9008543), $\mathrm{a}=3.1473 \AA$ ) and $\mathrm{Zr}$ (high-temperature allotrope, COD no. 9008559), $\mathrm{a}=3.62 \AA$ ), lies between the corresponding values of the two bcc alloys.

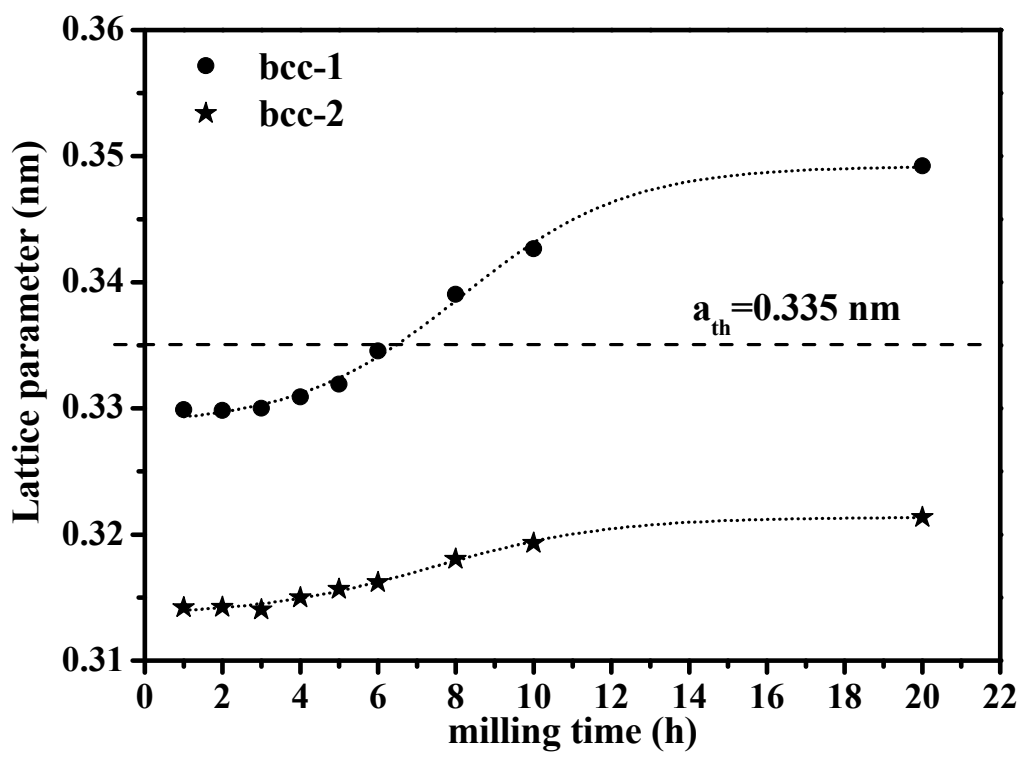

Figure 2. Experimental lattice parameters of bcc-1 and bcc-2 phases for all pTNTMZ specimens milled between 1 and $20 \mathrm{~h}$. Dashed line shows the theoretical lattice parameter for a unique TiNbTaMoZr HEA, calculated by the mixing law. 
Representative SEM images are shown for pTNTMZ1h, pTNTMZ4h, pTNTMZ6h and pTNTMZ10h (Figure 3), where a decrease in particle size with milling time is observed. Particles above $50 \mu \mathrm{m}$ were not visible when milling time reached $10 \mathrm{~h}$. Indeed, the micrometric particle agglomerates that were detected were formed by submicrometric particles, as a typical morphology of powders synthesized by dry milling processes [24].

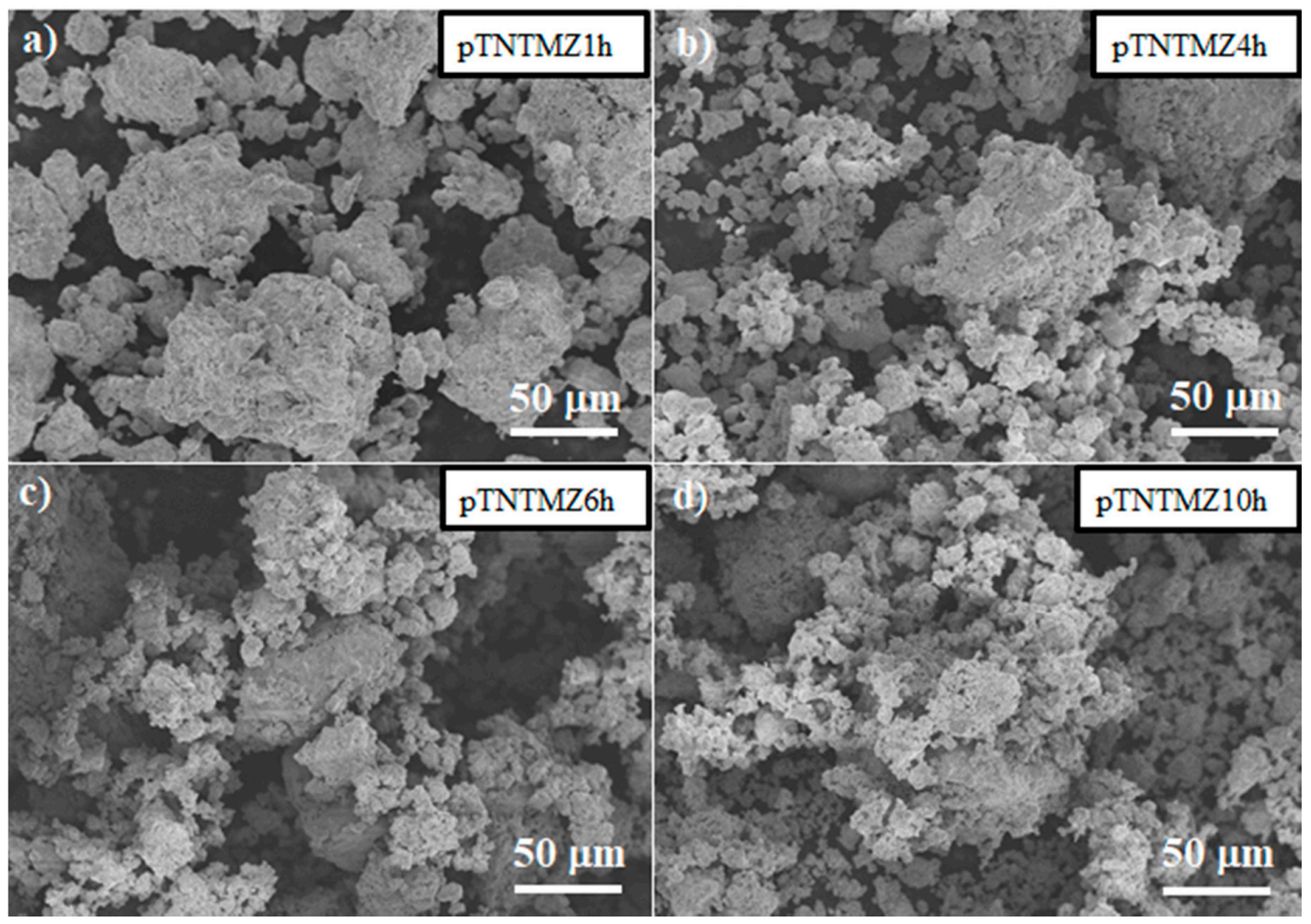

Figure 3. SEM images for (a) pTNTMZ1h, (b) pTNTMZ4h, (c) pTNTMZ6h and (d) pTNTMZ10h showing the evolution of the morphology and size of particles with the milling time.

To corroborate the element distribution of the various transition metals in the selected optimized as-synthesized pTNTMZ10h pattern, an SEM-EDS mapping was carried out (Figure 4). At first sight, good homogenization could be observed with the different transition metals distributed throughout the particles shown. Their calculated average atomic percentages (determined from 20 EDS points) indicate a nearly equiatomic alloy $\mathrm{TiNb}_{0,91} \mathrm{Ta}_{0.92} \mathrm{Mo}_{0.90} \mathrm{Zr}_{0.97}(\mathrm{Ti}=21.3 \pm 1.6 ; \mathrm{Nb}=19.4 \pm 0.8 ; \mathrm{Ta}=19.5 \pm 1.2$; $\mathrm{Mo}=19.1 \pm 1.5 ; \mathrm{Zr}=20.7 \pm 3.9)$. The amount of oxygen was practically negligible in all measurements, and always remained below the quantification limit of the SEM detector. Moreover, due to the presence of Ti, Nb, Ta, Mo and Ta throughout the particle, it is expected that these bcc alloys are, in fact, two TiNbTaMoZr-based HEAs. These results are in good agreement with previous work [26,27], where two bcc-TNTMZ alloys were also obtained. 


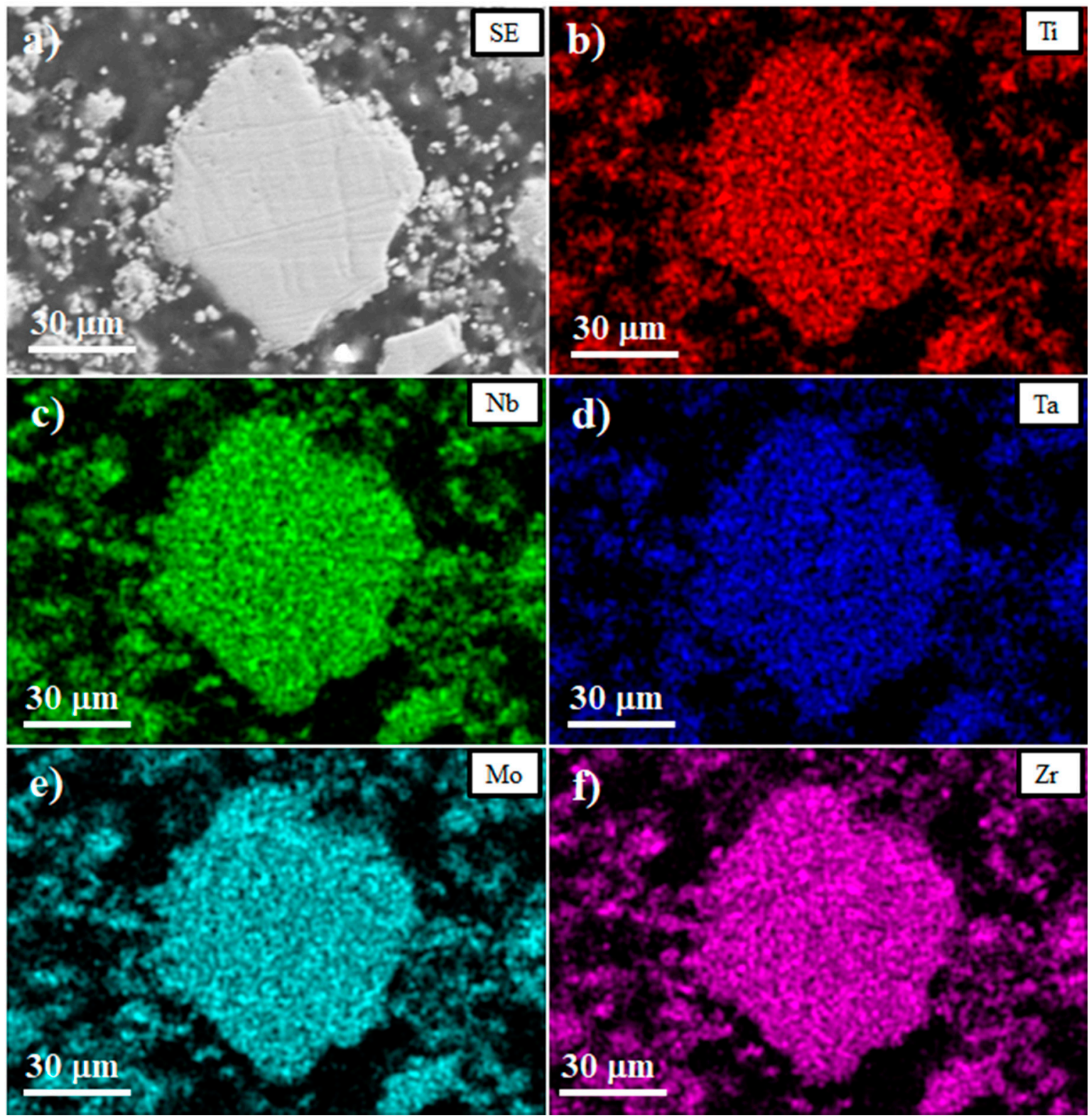

Figure 4. SEM image and EDS-mapping of the pTNTMZ10h specimen showing the distribution of the different transition metals. (a) Secondary electron (SE) image, (b) titanium, (c) niobium, (d) tantalum, (e) molybdenum and (f) zirconium.

An HRTEM study was carried out on the optimized pTNTMZ10h specimen (Figure 5) to corroborate the formation of the two bcc- 1 and bcc-2 alloys detected by XRD. This study showed an HRTEM image for a particle and its corresponding FFT. In the annular electron diffraction pattern, two clear rings assigned to the (110) crystallographic planes for the bcc- 1 and bcc- 2 alloys can be observed, whereby the interplanar distances are $0.243 \mathrm{~nm}$ and $0.225 \mathrm{~nm}$, respectively. Both crystallographic planes could also be observed in the lower HRTEM images of Figure 5, where the same interplanar distances could be calculated. Several other points were characterized in the FFT annular electron diffraction pattern, such as the (200) and (221) crystallographic planes for the majority bcc-2 alloy, whose interplanar distances were of $0.158 \mathrm{~nm}$ and $0.128 \mathrm{~nm}$, respectively. These distances and crystallographic planes are in concordance with the most intense peaks found in the XRD patterns (Figure 1). These assertions, together with the absence of other diffraction spots, corroborate the unique formation of these two bcc-1 and bcc-2 TiNbTaZrMo alloys. 


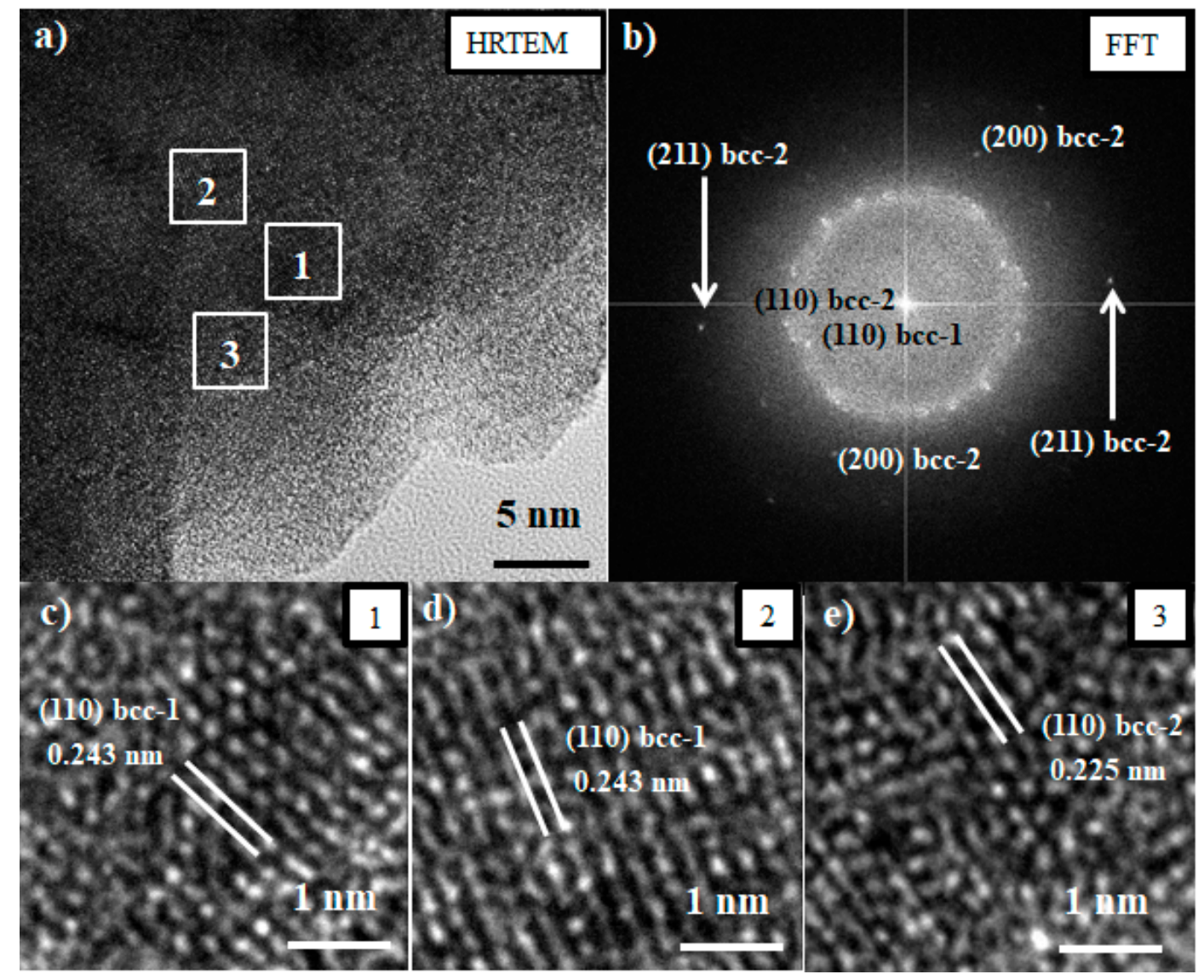

Figure 5. (a) High-resolution transmission electron microscopy (HRTEM) and (b) the corresponding fast Fourier transform (FFT) images for the pTNTMZ10h. Squares on the upper left images correspond to the magnification areas marked in the lower left HRTEM images. (c) Area no.1, (d) area no. 2 and (e) area no. 3

\subsection{Consolidation of the TiNbTaMoZr-Based HEA.}

The selected optimized specimen, that is, pTNTMZ10h, was pressureless sintered at $1450{ }^{\circ} \mathrm{C}$ and $1500{ }^{\circ} \mathrm{C}$, for $1 \mathrm{~h}$ of dwell time and $5{ }^{\circ} \mathrm{C} \mathrm{min}-1$ of heating and cooling rates. Firstly, it is important to highlight that no porosity was observed in later observations by optical and scanning electron microscopes, suggesting the full densification of both specimens. Thus, these two specimens, labeled as sTNTMZ_1450 ${ }^{\circ} \mathrm{C}$ and sTNTMZ_ $1500{ }^{\circ} \mathrm{C}$, showed almost identical XRD patterns (Figure 6) and the alloy remained practically invariant at the two sintering temperatures. As was expected for this TiNbTaMoZr-based HEA, a majority phase corresponding to a bcc phase with Im3m SGS was detected. The magnification of the XRD signal around the (110) crystallographic plane, displayed in the inset of Figure 6, showed the aforementioned and distinguishable bcc- 1 and bcc-2 phases for the as-synthesized pTNTMZ10h powder specimen.

From the (110) crystallographic planes, the lattice parameters for the bcc- 1 and bcc- 2 alloys in both sintered specimens can be calculated as $0.325 \pm 0.001 \mathrm{~nm}$ and $0.324 \pm 0.001 \mathrm{~nm}$ respectively, thereby corroborating the stability reached at $1450{ }^{\circ} \mathrm{C}$. By comparison with the corresponding bcc- 1 and bcc- 2 of the pTNTMZ10h specimen $(0.342 \mathrm{~nm}$ and $0.319 \mathrm{~nm}$ for bcc- 1 and bcc-2, respectively, see Figure 2), the lattice parameter of the bcc- 1 structure was reduced by $5 \%$, and the bcc- 2 increased by $1.5 \%$. This result suggests the outward migration of $\mathrm{Zr}$ metal atoms from the bcc-1 alloy during sintering. In this context, in the XRD patterns of both sintered specimens (Figure 6), a less intense peak was detected that could be assigned to a Ti-Zr alloy with a hexagonal close-packed structure, $\mathrm{P} 63 / \mathrm{mmc}$ SGS. This phase assignment could be validated by the displacements of the 2theta position in 
comparison with the XRD patterns of both single metals, which shows the same hcp structure and SGS (ref. no. 9008517 and 9008523 in the COD for Ti and Zr, respectively) promoted by the total solubility between $\mathrm{Ti}$ and $\mathrm{Zr}$ metals and not from $\mathrm{Zr}$ with the other $\mathrm{Nb}$, Ta and Mo transition metals [30].

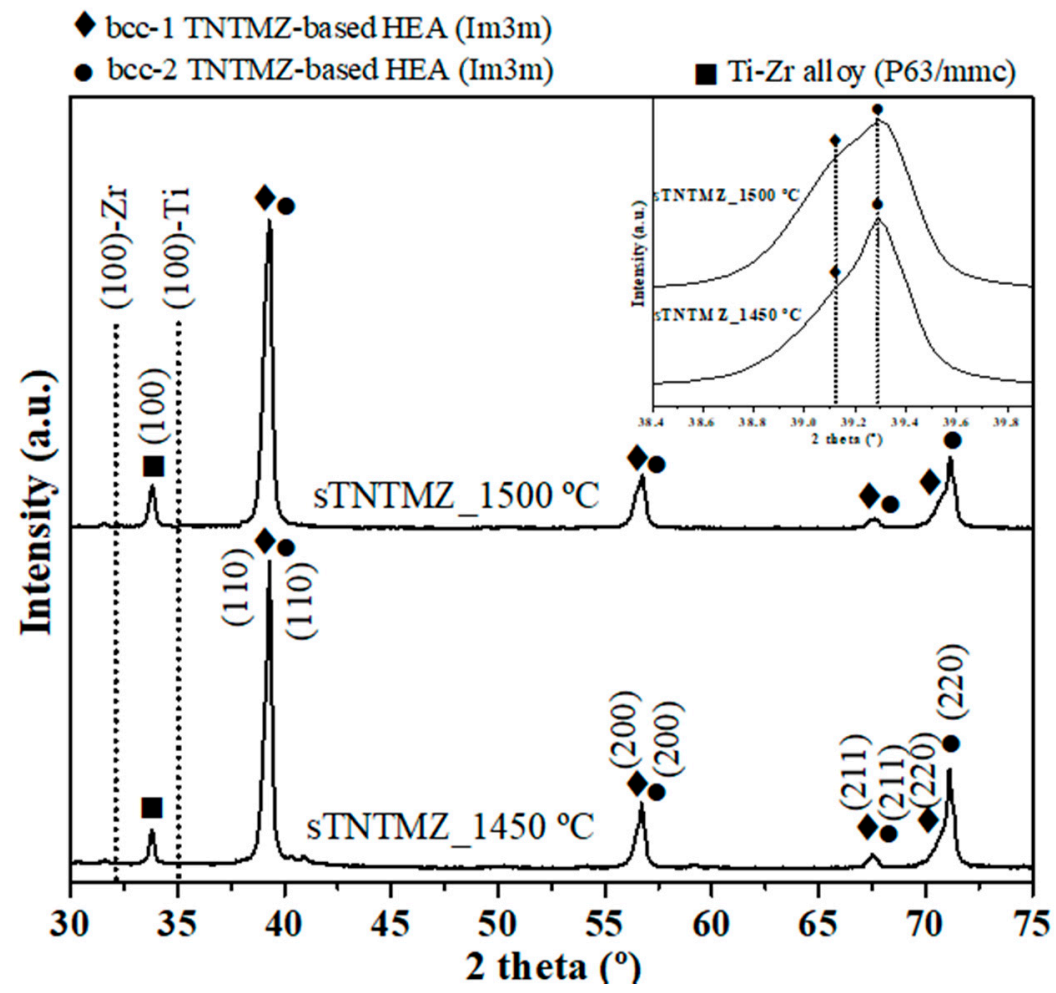

Figure 6. XRD patterns of the sintered sTNTMZ_1450 ${ }^{\circ} \mathrm{C}$ and sTNTMZ_1500 ${ }^{\circ} \mathrm{C}$ specimens. Between brackets: the crystallographic planes for each phase. Dotted lines are used to mark the position of the (100) crystallographic plane position for hcp-Ti and hcp-Zr. Inset: Magnification of the XRD patterns in the 38.4-39. $9^{\circ} 2 \theta$ range. Dotted lines are used to mark the invariant position of the (110) crystallographic planes for both bcc-1 and bcc-2 phases.

Since the XRD patterns in the two sintered specimens are identical, only the microstructure for the sTNTMZ $1450^{\circ} \mathrm{C}$ was studied. Figure 7a shows an SEM micrograph of a partial area of the polished surface with no significant porosity observed. Two differentiated microstructural phases were detected: a phase formed mainly of equiaxed grains with a range size of 1-3 $\mu \mathrm{m}$ in dark contrast; and what seems to be a continuous matrix phase in bright contrast. By EDS point analysis at both phases, the following average compositions in atomic percentages were determined as: a) $\mathrm{Ti}=22.9 \pm 1.6 ; \mathrm{Nb}=19.3 \pm 1.6$; $\mathrm{Ta}=19.4 \pm 1.9 ; \mathrm{Mo}=16.3 \pm 1.4 ; \mathrm{Zr}=21.4 \pm 2.8$, for the dark grain phase; and $\mathrm{b}) \mathrm{Ti}=15.4 \pm 2.8 ;$ $\mathrm{Nb}=23.1 \pm 2.6 ; \mathrm{Ta}=21.1 \pm 2.6 ; \mathrm{Mo}=23.8 \pm 1.9 ; \mathrm{Zr}=16.2 \pm 2.6$, for the matrix phase, which correspond to $\mathrm{TiNb}_{0.84} \mathrm{Ta}_{0.84} \mathrm{Mo}_{0.71} \mathrm{Zr}_{0.93}$ and $\mathrm{TiNb}_{1.53} \mathrm{Ta}_{1.40} \mathrm{Mo}_{1.60} \mathrm{Zr}_{0.94}$, respectively. Therefore, this observation corroborates that the bcc- 1 and bcc- 2 alloys were, in fact, two TiNbTaMoZr-based HEA alloys, with different stoichiometry that produce different contrasts in the SEM micrographs.

Notice that the composition of the matrix phase alloy is clearly the lowest $\mathrm{Ti}$ and $\mathrm{Zr}$ amount in comparison with the nominal percentage (15.4 at.\% of Ti and 16.2 at.\% of $\mathrm{Zr}$ vs. 20 at.\% each for Ti and $\mathrm{Zr}$ metals). This result could be linked to the formation of the hcp Ti-Zr-based alloy previously detected by XRD (Figure 6). The lower diffusion coefficient of $\mathrm{Zr}$ atoms in the $\mathrm{Nb}$, Ta and Mo bcc structures could produce its segregation from the TiNbTaMoZr alloys, and the short redistribution of elements created during the mechanical alloying offers a non-negligible amount of the other hcp metals, mainly the hcp-Ti. Therefore, it can be assumed that this Zr-Ti alloy is masked by the two major bcc- 1 and bcc- 2 phases detected in the XRD analysis, and therefore becomes untraceable through SEM examination. In comparison with previous work [25-27] that focused on the same TiNbTaMoZr-based 
HEAs, a potential biomaterial has been obtained with the same two majority bcc- 1 and bcc 2 phases, but with the advantage of equiaxed particles, instead of a dendritic structure with a heterogeneity composition and interdendritic microsegregation [27]. Moreover, with this MA route, it was only necessary to reach a sintering temperature, which is lower than the melting temperatures of $\mathrm{Ti}, \mathrm{Nb}, \mathrm{Ta}$, $\mathrm{Mo}$ and $\mathrm{Zr}$ transition metals as required for the arc-melting route.

\subsection{Micromechanical Behavior of the TiNbTaMoZr-Based HEA.}

In order to estimate the potential use of this TiNbTaMoZr-based HEA material as a biomaterial for bone-replacement implants, instrumented microindentation tests were carried out (15 tests) on the sTNTMZ1450 ${ }^{\circ} \mathrm{C}$ specimen. The hardness $(\mathrm{H})$ and Young's modulus $(\mathrm{E})$ were calculated according to Equations (4)-(6). Figure $7 \mathrm{~b}$ shows a representative indentation mark inflicted on the surface of the specimen and, Figure $7 \mathrm{c}$ a series of load-displacement $(\mathrm{P}-\mathrm{h})$ curves of the tests carried out, respectively. As can be observed, the indentation area included a significant amount of both bcc phases. The values obtained can therefore be extrapolated as the properties of the full specimen.
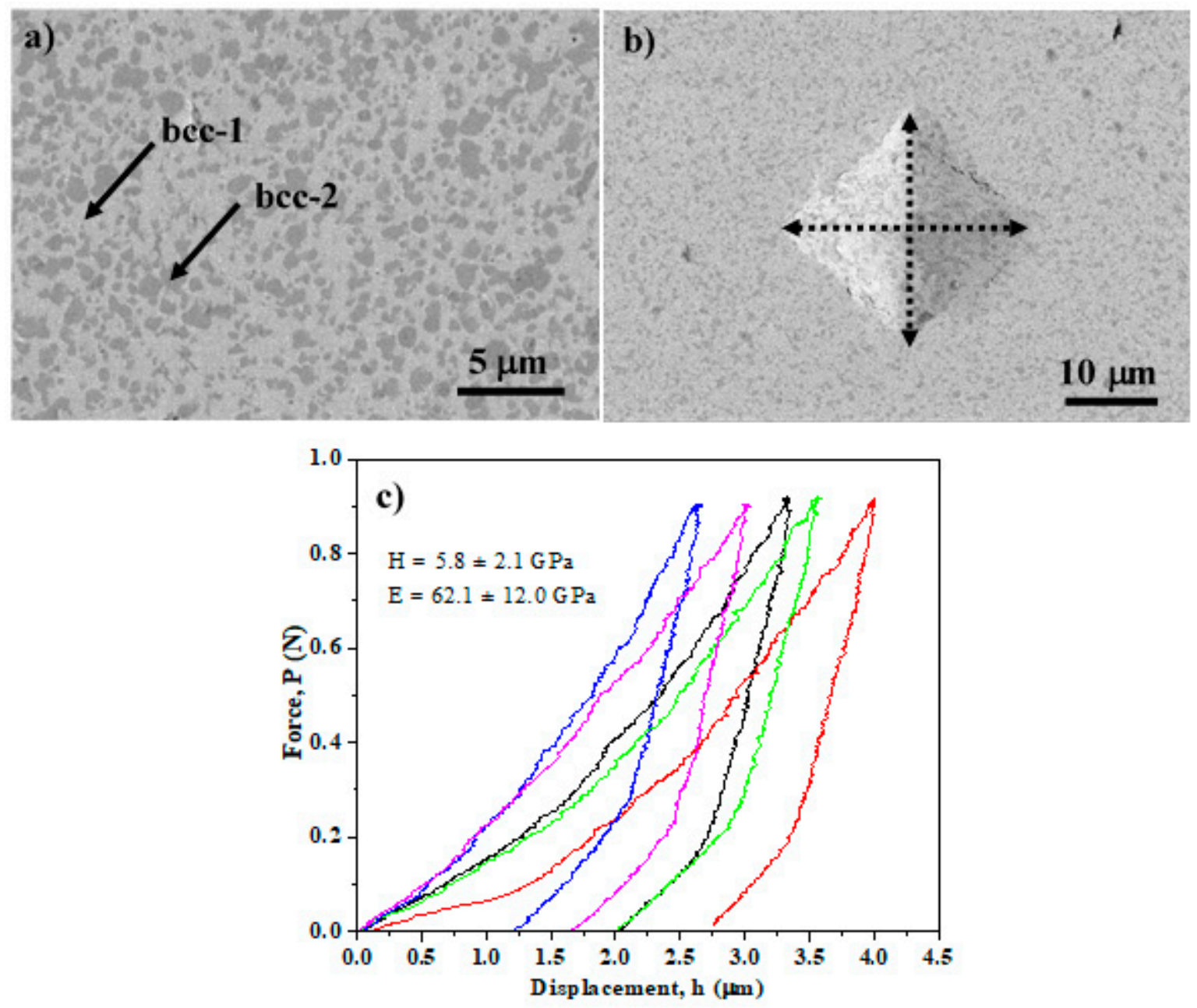

Figure 7. (a) SEM image, (b) indentation mark and (c) load-displacement $(\mathrm{P}-\mathrm{h})$ curve obtained from the microindentation tests, for the sTNTMZ_1450 ${ }^{\circ} \mathrm{C}$ specimen.

Average values of microhardness $(\mathrm{H})$ and Young's modulus $(\mathrm{E})$ were determined as $5.8 \pm 1.1$ GPa and $62.1 \pm 12.0 \mathrm{GPa}$, respectively. Regarding the microhardness, this value is superior to those reported for similar HEAs. In this context, NbTaMoV showed a hardness value of 4.9 GP [34], $5.3 \mathrm{GPa}$ for MoNbTaVW, 3.0 GPa for $\mathrm{NbTiV}_{2} \mathrm{Zr}$ [35], 5.8 GPa for $\mathrm{AlMo}_{0.5} \mathrm{NbTa}_{0.5} \mathrm{TiZr}$ [36] and 4.9 GPa for the same TiNbTaMoZr system [25]. These hardness values were significantly lower than those obtained in 
this work, which could be largely attributed to their closer composition to a single TiNbTaMoZr HEA (2theta distance values between the (110) peaks of both bcc-1 and bcc-2 TiNbTaMoZr-based HEAs in the XRD patterns are $0.2^{\circ}$ (see inset of Figure 6) vs. $1^{\circ}$ in the aforementioned references). This more homogeneous composition leads to a hardening effect as a consequence of a more accused solid-solution strengthening $[37,38]$. Moreover, the low grain sizes achieved in this work (approximately 1-2 $\mu \mathrm{m}$ vs. $100 \mu \mathrm{m}$ [25-27]) could exert some influence on the increased hardness. Thus, high hardness constitutes an essential characteristic of the permanent bone implant made of metallic materials [39].

Regarding Young's modulus, the value obtained (62.1 GPa) was much lower than the cp-Ti, and the Ti6Al4V commonly used as a biomaterial for bone implants, which is usually greater than 100 GPa [40]. Furthermore, the beta-Ti alloys use $\mathrm{Nb}$, Ta and Mo as beta-phase stabilizer metals to reduce Young's modulus and, consequently, to reduce the detrimental stress-shielding phenomenon [41]. Those beta-Ti alloys exhibit E values of approximately $60 \mathrm{GPa}$, which is similar to that of the TNTMZ-based HEA material developed herein $[14,42,43]$.

It is important to note that although this TiNbTaMoZr-based HEA material is intended for bone-replacement implants and some of the most important mechanical properties are the hardness and the Young's modulus, better mechanical performances (as an example, an increase in the yield strength) are always welcome. Thus, in particular for HEAs, the increase in strength and ductility have been well documented for the fcc Fe-based HEA and attributed to the microband-induced plasticity (MBIP) effect [44], the transformation-induced plasticity (TRIP) and the twinning-induced plasticity (TWIP) effect [45], just recently also observed in a bcc Ti-rich HEA (Ti35Zr27.5Hf27.5Nb5Ta5) [46]. Therefore, the TiNbTaMoZr-based HEA developed in this work could follow these mechanisms of deformations.

\section{Conclusions}

In this work, a TiNbTaMoZr-based HEA material has been developed via mechanical alloying synthesis and subsequently through pressureless sintering following a powder metallurgy route.

This synthesis method, to the best of our knowledge, was carried out for the first time in a powder form and at room temperature, instead of the usual arc-melting route, which requires high temperatures to melt all the metals involved and where a bulk form is always obtained. These aspects enable the powders to be used for the manufacture of porous materials (foams) by powder metallurgy technologies, such as that of Binder Jetting additive manufacturing.

The phases obtained are two bcc-TiNbTaMoZr alloys, like those reported in previous work. However, the microstructure is formed of a homogeneous mix of two types of equiaxed particles instead of the dendritic and/or heterogeneous composition of grains and grain boundaries that can lead to the detriment of mechanical properties.

Finally, the hardness was higher than in the other Ti-based HEAs developed, with the consequent positive effect expected for bone implants. In contrast, Young's modulus was drastically reduced due to the bcc structure $(62.1 \pm 12.0 \mathrm{GPa})$ instead of the hcp structure for the usual cp-Ti and Ti6Al4V, which has a higher Young's modulus (above $100 \mathrm{GPa}$ ), which in turn can produce a positive effect on the reduction of the detrimental stress-shielding phenomena on bone implants.

Author Contributions: Conceptualization, E.C.; methodology, J.N., R.M. and E.C.; investigation, J.N., R.M. and C.G.-G.; validation, J.N., R.M. and R.E.S.F.; formal analysis, R.M. and E.C.; writing-review and editing, all authors; supervision, E.C. and R.E.S.F.; project administration, E.C and R.E.S.F.; funding acquisition, E.C. and R.E.S.F. All authors have read and agreed with the published version of the manuscript.

Funding: This work was financed in part by the VI Research Program of the University of Seville, under the project no. 2019/00000600.

Acknowledgments: The authors would like to thank the Instituto de Ciencia de Materiales de Sevilla (ICMS) for allowing us the use of its synthesis and consolidation devices Furthermore, the authors especially want to thank María Jesús Sayagués for her assistance in the TEM specimen's characterization.

Conflicts of Interest: The authors declare no conflict of interest. 


\section{References}

1. Unnithan, A.R.; Arathyram, R.; Kim, C.S. Electrospinning of Polymers for Tissue Engineering. Nanotechnol. Appl. Tissue Eng. 2015, 45-55. [CrossRef]

2. Yeh, J.-W. Alloy Design Strategies and Future Trends in High-Entropy Alloys. JOM 2013, 65, $1759-1771$. [CrossRef]

3. Zhang, Y.; Zhou, Y.J.; Lin, J.P.; Chen, G.L.; Liaw, P.K. Solid-Solution Phase Formation Rules for Multi-component Alloys. Adv. Eng. Mater. 2008, 10, 534-538. [CrossRef]

4. Guo, S.; Hu, Q.; Ng, C.; Liu, C. More than entropy in high-entropy alloys: Forming solid solutions or amorphous phase. Intermettalics 2013, 41, 96-103. [CrossRef]

5. Ye, Y.; Wang, Q.; Lu, J.; Liu, C.; Yang, Y. High-entropy alloy: Challenges and prospects. Mater. Today 2016, 19, 349-362. [CrossRef]

6. Pickering, E.J.; Jones, N.G. High-entropy alloys: A critical assessment of their founding principles and future prospects. Int. Mater. Rev. 2016, 61, 183-202. [CrossRef]

7. Cantor, B.; Chang, I.; Knight, P.; Vincent, A. Microstructural development in equiatomic multicomponent alloys. Mater. Sci. Eng. A 2004, 375, 213-218. [CrossRef]

8. Senkov, O.; Wilks, G.; Miracle, D.; Chuang, C.; Liaw, P. Refractory high-entropy alloys. Intermettalics 2010, 18, 1758-1765. [CrossRef]

9. Miracle, D.B.; Miller, J.D.; Senkov, O.; Woodward, C.; Uchic, M.D.; Tiley, J. Exploration and Development of High Entropy Alloys for Structural Applications. Entropy 2014, 16, 494-525. [CrossRef]

10. Murty, B.; Yeh, J.; Ranganathan, S. High Entropy Alloys. High Entropy Alloys 2014, 10, 1-12.

11. Li, Y.; Yang, C.; Zhao, H.; Qu, S.; Li, X.; Li, Y. New Developments of Ti-Based Alloys for Biomedical Applications. Materials. 2014, 7, 1709-1800. [CrossRef]

12. Agrawal, C.M. Reconstructing the human body using biomaterials. JOM 1998, 50, 31-35. [CrossRef]

13. Shi, L.; Wang, L.; Duan, Y.; Lei, W.; Wang, Z.; Li, J.; Fan, X.; Li, X.; Li, S.; Guo, Z. The Improved Biological Performance of a Novel Low Elastic Modulus Implant. PLoS ONE 2013, 8, e55015. [CrossRef]

14. Geetha, M.; Singh, A.; Asokamani, R.; Gogia, A. Ti based biomaterials, the ultimate choice for orthopaedic implants - A review. Prog. Mater. Sci. 2009, 54, 397-425. [CrossRef]

15. Calin, M.; Gebert, A.; Ghinea, A.C.; Gostin, P.F.; Abdi, S.; Mickel, C.; Eckert, J. Designing biocompatible Ti-based metallic glasses for implant applications. Mater. Sci. Eng. C 2013, 33, 875-883. [CrossRef] [PubMed]

16. Matsuno, H. Biocompatibility and osteogenesis of refractory metal implants, titanium, hafnium, niobium, tantalum and rhenium. Biomaterials 2001, 22, 1253-1262. [CrossRef]

17. Hynowska, A.; Pellicer, E.; Fornell, J.; González, S.; Van Steenberge, N.; Suriñach, S.; Gebert, A.; Calin, M.; Eckert, J.; Baró, M.D.; et al. Nanostructured $\beta$-phase Ti-31.0Fe-9.0Sn and sub- $\mu$ m structured Ti-39.3Nb-13.3Zr-10.7Ta alloys for biomedical applications: Microstructure benefits on the mechanical and corrosion performances. Mater. Sci. Eng. C 2012, 32, 2418-2425. [CrossRef]

18. Meng, Q.; Guo, S.; Liu, Q.; Hu, L.; Zhao, X. A $\beta$-type TiNbZr alloy with low modulus and high strength for biomedical applications. Prog. Nat. Sci. 2014, 24, 157-162. [CrossRef]

19. Long, M.; Rack, H. Titanium alloys in total joint replacement-A materials science perspective. Biomaterials 1998, 19, 1621-1639. [CrossRef]

20. Hussein, A.H.; Gepreel, M.A.-H.; Gouda, M.K.; Hefnawy, A.M.; Kandil, S.H. Biocompatibility of new Ti-Nb-Ta base alloys. Mater. Sci. Eng. C 2016, 61, 574-578. [CrossRef]

21. Chicardi, E.; Gutiérrez-González, C.; Sayagués, M.; García-Garrido, C. Development of a novel TiNbTa material potentially suitable for bone replacement implants. Mater. Des. 2018, 145, 88-96. [CrossRef]

22. Chicardi, E.; García-Garrido, C.; Sayagués, M.; Torres, Y.; Amigó, V.; Aguilar, C. Development of a novel fcc structure for an amorphous-nanocrystalline Ti-33Nb-4Mn (at.\%) ternary alloy. Mater. Charact. 2018, 135, 46-56. [CrossRef]

23. Singh, S.; Wanderka, N.; Murty, B.; Glatzel, U.; Banhart, J. Decomposition in multi-component AlCoCrCuFeNi high-entropy alloy. Acta Mater. 2011, 59, 182-190. [CrossRef]

24. Suryanarayana, C. Mechanical alloying and milling. Prog. Mater. Sci. 2001, 46, 1-184. [CrossRef]

25. Wang, S.-P.; Xu, J. TiZrNbTaMo high-entropy alloy designed for orthopedic implants: As-cast microstructure and mechanical properties. Mater. Sci. Eng. C 2017, 73, 80-89. [CrossRef] [PubMed] 
26. Todai, M.; Nagase, T.; Hori, T.; Matsugaki, A.; Sekita, A.; Nakano, T. Novel TiNbTaZrMo high-entropy alloys for metallic biomaterials. Scr. Mater. 2017, 129, 65-68. [CrossRef]

27. Nagase, T.; Todai, M.; Hori, T.; Nakano, T. Microstructure of equiatomic and non-equiatomic Ti-Nb-Ta-Zr-Mo high-entropy alloys for metallic biomaterials. J. Alloy. Compd. 2018, 753, 412-421. [CrossRef]

28. Popov, V.V.; Katz-Demyanetz, A.; Koptyug, A.; Bamberger, M. Selective electron beam melting of A10.5CrMoNbTa0.5 high entropy alloys using elemental powder blend. Heliyon 2019, 5, e01188. [CrossRef]

29. Oliver, W.; Pharr, G. Measurement of hardness and elastic modulus by instrumented indentation: Advances in understanding and refinements to methodology. J. Mater. Res. 2004, 19, 3-20. [CrossRef]

30. Davis, J.R. Handbook of Materials for Medical Devices; ASM International: Cleveland, OH, USA, 2003.

31. Li, Y.; Jahr, H.; Lietaert, K.; Pavanram, P.; Yilmaz, A.; Fockaert, L.; Leeflang, M.; Pouran, B.; Gonzalez-Garcia, Y.; Weinans, H.; et al. Additively manufactured biodegradable porous iron. Acta Biomater. 2018, 77, 380-393. [CrossRef]

32. Zhu, S.; Huang, N.; Xu, L.; Zhang, Y.; Liu, H.; Sun, H.; Leng, Y. Biocompatibility of pure iron: In vitro assessment of degradation kinetics and cytotoxicity on endothelial cells. Mater. Sci. Eng. C 2009, 29, 1589-1592. [CrossRef]

33. Liu, B.; Zheng, Y. Effects of alloying elements (Mn, Co, Al, W, Sn, B, C and S) on biodegradability and in vitro biocompatibility of pure iron. Acta Biomater. 2011, 7, 1407-1420. [CrossRef]

34. Gorsse, S.; Nguyen, M.; Senkov, O.; Miracle, D. Database on the mechanical properties of high entropy alloys and complex concentrated alloys. Data Brief 2018, 21, 2664-2678. [CrossRef] [PubMed]

35. Senkov, O.; Senkova, S.; E Woodward, C.; Miracle, D. Low-density, refractory multi-principal element alloys of the $\mathrm{Cr}-\mathrm{Nb}-\mathrm{Ti}-\mathrm{V}-\mathrm{Zr}$ system: Microstructure and phase analysis. Acta Mater. 2013, 61, 1545-1557. [CrossRef]

36. Senkov, O.; Senkova, S.; Woodward, C. Effect of aluminum on the microstructure and properties of two refractory high-entropy alloys. Acta Mater. 2014, 68, 214-228. [CrossRef]

37. Wu, Y.; Cai, Y.; Chen, X.; Wang, T.; Si, J.; Wang, L.; Wang, Y.; Hui, X. Phase composition and solid solution strengthening effect in TiZrNbMoV high-entropy alloys. Mater. Des. 2015, 83, 651-660. [CrossRef]

38. Toda-Caraballo, I.; Rivera-Díaz-Del-Castillo, P.E. Modelling solid solution hardening in high entropy alloys. Acta Mater. 2015, 85, 14-23. [CrossRef]

39. Gan, J.; Berndt, C. Plasma Surface Modification of Metallic Biomaterials. In Surface Coating and Modification of Metallic Biomaterials; Elsevier BV: Amsterdam, The Netherlands, 2015; pp. 103-157.

40. Breme, J.; Eisenbarth, E.; Biehl, V. Titanium and its Alloys for Medical Applications. In Titanium and Titanium Alloys; Wiley: Hoboken, NJ, USA, 2005; pp. 423-451.

41. Ibrahim, H.; Esfahani, S.N.; Poorganji, B.; Dean, D.; Elahinia, M. Resorbable bone fixation alloys, forming, and post-fabrication treatments. Mater. Sci. Eng. C 2017, 70, 870-888. [CrossRef]

42. Kolli, R.P.; Devaraj, A. A Review of Metastable Beta Titanium Alloys. Metabolism 2018, 8, 506. [CrossRef]

43. Niinomi, M.; Liu, Y.; Nakai, M.; Liu, H.; Li, H. Biomedical titanium alloys with Young's moduli close to that of cortical bone. Regen. Biomater. 2016, 3, 173-185. [CrossRef]

44. Wang, Z.; Baker, I.; Guo, W.; Poplawsky, J.D. The effect of carbon on the microstructures, mechanical properties, and deformation mechanisms of thermo-mechanically treated Fe40.4Ni11.3Mn34.8Al7.5Cr6 high entropy alloys. Acta Mater. 2017, 126, 346-360. [CrossRef]

45. Li, Z.; Tasan, C.C.; Springer, H.; Gault, B.; Raabe, D. Interstitial atoms enable joint twinning and transformation induced plasticity in strong and ductile high-entropy alloys. Sci. Rep. 2017, 7, 40704. [CrossRef]

46. Eleti, R.R.; Klimova, M.; Tikhonovsky, M.; Stepanov, N.; Zherebtsov, S. Exceptionally high strain-hardening and ductility due to transformation induced plasticity effect in Ti-rich high-entropy alloys. Sci. Rep. 2020, 10, 1-8. [CrossRef] [PubMed]

Publisher's Note: MDPI stays neutral with regard to jurisdictional claims in published maps and institutional affiliations. 